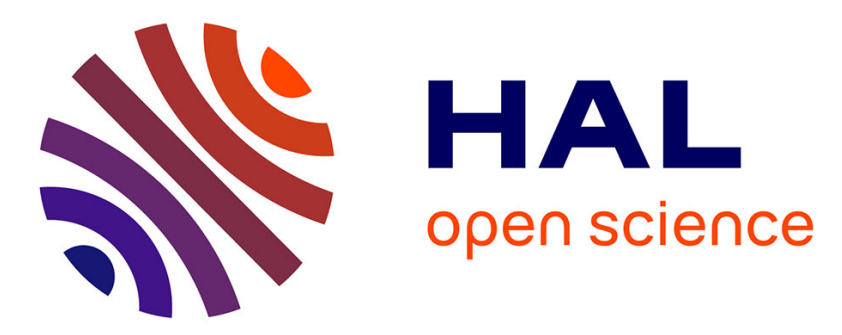

\title{
Improvement of 2D-PAGE resolution of human, porcine and canine follicular fluid: comparison of two immunodepletion columns
}

Somayyeh Fahiminiya, S. Roche, Nadine Gérard

\section{- To cite this version:}

Somayyeh Fahiminiya, S. Roche, Nadine Gérard. Improvement of 2D-PAGE resolution of human, porcine and canine follicular fluid: comparison of two immunodepletion columns. Reproduction in Domestic Animals, 2012, 47 (5), pp.e67-e70. 10.1111/j.1439-0531.2011.01939.x . hal-01129661

\section{HAL Id: hal-01129661 \\ https://hal.science/hal-01129661}

Submitted on 18 Dec 2017

HAL is a multi-disciplinary open access archive for the deposit and dissemination of scientific research documents, whether they are published or not. The documents may come from teaching and research institutions in France or abroad, or from public or private research centers.
L'archive ouverte pluridisciplinaire HAL, est destinée au dépôt et à la diffusion de documents scientifiques de niveau recherche, publiés ou non, émanant des établissements d'enseignement et de recherche français ou étrangers, des laboratoires publics ou privés. 


\title{
Improvement of 2D-PAGE Resolution of Human, Porcine and Canine Follicular Fluid: Comparison of Two Immunodepletion Columns
}

\author{
S Fahiminiya ${ }^{1}$, S Roche Rे3 $^{2,3}$ and Gérard ${ }^{1}$ \\ ${ }^{1}$ Physiologie de la Reproduction et des Comportements, UMR 6175, INRA, Nouzilly, France; ${ }^{2}$ Institut de Génétique humaine du CNRS, UPR1142, \\ Montpellier, France; ${ }^{3}$ Plateforme de Protéomique Clinique, Hôpital Saint-Eloi, Montpellier, France
}

\begin{abstract}
Contents
Follicular fluid provides the microenvironment within which somatic cells proliferate and differentiate, and the oocyte matures. It contains a number of soluble factors implicated in various stages of follicular development, most of them being functionally unknown. The presence of several high-abundance proteins, mainly originating from the blood circulation, is a major challenge of follicular fluid proteomic analysis, as these proteins can mask or decrease the visualization of follicle-specific proteins. In this study, we evaluated the efficiency of two immunodepletion columns (ProteomeLab ${ }^{\mathrm{TM}}$ IgY-HSA and MARS-6) on follicular fluids of human, porcine and canine prior to 2D-PAGE. Our results showed that both columns were suitable to remove some of the high-abundance proteins present in human and canine follicular fluid. In conclusion, we demonstrated that the immunodepletion strategy enables the detection of new protein spots, increases resolution and highly improves the intensity of low-abundance proteins by $2 \mathrm{D}-\mathrm{PAGE}$.
\end{abstract}

\section{Introduction}

Follicular fluid (FF) accumulates in the antrum of growing follicles. It provides the microenvironment within which somatic cells proliferate and differentiate, and the oocyte matures. Previous proteomic studies on follicular fluid of various species (Cabrera et al. 1985; Angelucci et al. 2006; Fahiminiya et al. 2010) demonstrated that it contains several high-abundance proteins (albumin, immunoglobulins, alpha-1-antitrypsin, transferrin and haptoglobin), which constitute approximately $85-90 \%$ of the total protein mass (Jacobs et al. 2005). The presence of these high-abundance proteins in follicular fluid can preclude the identification, or even the detection, of follicle-specific proteins (low-abundance proteins) which locally produced and secreted by ovarian cells into the follicular fluid (Fortune et al. 2004). Detection and identification of these low-abundance proteins like growth or differentiation factors in follicular fluid would help to better understand ovarian follicular growth and oocyte development in mammals. Therefore, an efficient approach to overcome this challenge might be to remove some high-abundance plasma proteins from follicular fluid prior to its proteomic analysis. Recently, the application of immunodepletion columns has been raised to remove up to 20 high-abundance proteins from human biological fluids. To our knowledge, no pre-fractionation method was developed specially for follicular fluid. In this study, we evaluated the efficiency of two immunodepletion columns (ProteomeLab ${ }^{\mathrm{TM}}$ IgY-HSA and MARS-6) to remove high-abundance proteins from human (HFF), porcine (PFF) and canine (CFF) follicular fluids prior to 2D-PAGE analysis. These two columns are based on either immunoglobulin $\mathrm{G}$ ( $\mathrm{IgG}$ ) in mammals (Martosella et al. 2005) or immunoglobulin yolk (IgY) in chickens (Zhang 2003; Huang et al. 2005; Linke et al. 2007). Indeed, the immunodepletion of follicular fluid allowed us to visualize several peptides and proteins on $2 \mathrm{D}$ gels, previously masked by high-abundance proteins.

\section{Material and Methods}

Porcine ovaries were collected at the slaughterhouse, and the follicular fluids were punctured from ovaries with a 20-G needle. Canine follicular fluids were aspirated from ovaries collected by ovariectomy (Fahiminiya et al. 2010). Human follicular fluids were collected according to Guerif et al. (2003) method. In each species, the follicular fluid was collected from three different ovaries. After collection, follicular fluid samples were centrifuged for $10 \mathrm{~min}$ at $1500 \times \boldsymbol{g}$ and stored at $-80^{\circ} \mathrm{C}$ till immunodepletion step.

Two immunodepletion spin columns were used to remove high-abundance plasma proteins from the follicular fluids of human, porcine and canine species. As far as, we know these two immunodepletion methods has no side effect on the protein structure. All steps were performed at room temperature as recommended by the manufacturers. The depleted fractions were concentrated by $10-\mathrm{kDa}$ molecular mass cut-off centrifugal concentrators $\left(\right.$ Microcon $^{\circledR}$; Millipore, Bedford, MA, USA), and the $\mathrm{pH}$ of fractions was neutralized by $50 \mathrm{~mm}$ Tris $\mathrm{pH}$ 8.8. Names and properties of the two immunodepletion columns are presented in Table 1.

All the chemicals and materials used for proteomic analysis were purchased from Bio-Rad (Marnes-laCoquette, France), unless otherwise indicated. The protein assay and 2D-PAGE analysis were performed as previously described (Fahiminiya et al. 2010). Briefly, the total protein content of crude and depleted follicular fluids was determined using DC (detergent compatible) assay with bovine serum albumin as standard (Pierce, Rockford, IL, USA) and statistically analysed by the non-parametric Kruskal-Wallis test. For analytical separations, 2D-PAGE was performed on three individual samples in each species: $100 \mu \mathrm{g}$ of proteins was loaded upon ReadyStrip ${ }^{\mathrm{TM}}$ IPG (11-cm IPG strips, pH 
Table 1. Major characteristics of the evaluated immunodepletion columns

\begin{tabular}{lcc}
\hline Binding specificity & $\begin{array}{c}\text { ProteomeLab } \\
\text { IgY-HSA }\end{array}$ & $\begin{array}{c}\text { Multiple affinity removal } \\
\text { spin cartridge }- \text { human } 6 \\
\text { (MARS-6) }\end{array}$ \\
\hline Albumin & + & + \\
Alpha-1-Antitrypsin & - & + \\
Haptoglobulin & - & + \\
IgA & - & + \\
IgG & - & + \\
Transferrin & - & 14 \\
Loading capacity in $\mu 1$ & 10 & Spin columns \\
Method for immunodepletion & & \\
\hline
\end{tabular}

range 3-10) that were used for isoelectric focusing (IEF). After IEF, the strips were equilibrated with SDS-PAGE equilibration buffer containing DTT $(2 \%)$ and iodoacetamide $(2.5 \%)$. Equilibrated IPG strips were subjected to SDS-PAGE $(10 \%)$. Electrophoresis was run at $10 \mathrm{~mA}$ gel for $45 \mathrm{~min}$ and $200 \mathrm{~V}$ until the dye front reached the bottom of the gels $(5-6 \mathrm{~h})$. Gels were stained with silver nitrate and were scanned at 16-bit resolution by ImageScanner (Amersham Pharmacia Biotech, GE Healthcare Europe GmBH, Orsay, France). Resulting TIFF images were analysed with Progenesis work station software (version 2008; Nonlinear Dynamics Ltd, Newcastle upon Tyne, UK).

\section{Results and Discussion}

The major challenge of follicular fluid proteomic analysis is its high similarity with plasma, in which a few proteins (high abundance) constitute more than $80 \%$ of the total protein content. One efficient methodology prior to its proteomic analysis could be the depletion of high-abundance proteins, to visualize, and consequently identify some lower-abundance ones. The latter may be most probably produced locally by follicle cells. To our knowledge, no method has been developed to deplete follicular fluid before its proteomic analysis. Here, we compared the efficiency of two immunodepletion columns in three species, with the aim to determine whether the removal of high-abundant proteins could improve the resolution of 2D protein patterns of follicular fluid.

Depletion efficiency and reproducibility of Proteom$\mathrm{eLab}^{\mathrm{TM}}$ IgY-HSA and MARS-6 on HFF, PFF and CFF were determined after the measurement of the total protein content (Table 2) and 2D-PAGE analysis
(Fig. 1). The mean of total protein concentration of crude follicular fluids varied among species, the higher concentration being observed for PFF and the lower for HFF. In addition, both columns displayed the higher depletion efficiency $(87.27 \pm 2.56 \%$ and $81.81 \pm 3.65 \%$, respectively) for HFF. This can be explained by the fact that the antigens used in the immunodepletion columns are generated against human proteins.

Crude and depleted fractions of HFF, CFF and PFF were resolved by 2D-PAGE, to visualize the efficiency of the two immunodepletion columns tested (Fig. 1). The 2D-PAGE proteins profiles of crude follicular fluid of human, porcine and canine showed some similarities (Fig. 1, column A). Of note is the fact that some highabundance plasma proteins (especially albumin and immunoglobulins) were visualized as intense and large spots on the 2D-PAGE, which most probably mask lowabundance proteins. The total numbers of protein spots detected on the 2D-PAGE of crude PFF (794) was higher than on the crude HFF (592) and crude CFF (627). Although the total number of spots revealed by $2 \mathrm{D}-\mathrm{PAGE}$ has the same trend as the total protein concentration measured in the three species $(\mathrm{PFF}>\mathrm{CFF}>\mathrm{HFF})$, the reason of this difference among species remains unknown. It may be due to the higher quantity of some proteins or the presence of some species-specific peptidergic factors.

The 2D-PAGE protein profiles of depleted follicular fluids with ProteomeLab ${ }^{\mathrm{TM}}$ IgY-HSA showed that albumin was completely removed from $\mathrm{HFF}$ and CFF, but partially from PFF (Fig. 1, column B). This result is consistent with the depletion efficiency percentages that we measured for this column. The reason why albumin is completely removed from CFF, but not from PFF, is not clear. One possible hypothesis could be explained by a higher similarity of antigenic sites of albumin between human and canine, than between human and porcine. With the aim to evaluate the capacity of ProteomeLab ${ }^{\mathrm{TM}}$ IgY-HSA to bind non-specific proteins, 2D-PAGE was performed on the bound fraction of follicular fluid. We observed that only albumin was removed from follicular fluid of all species and no additional protein spot was visualized on 2D gels (data not shown).

The 2D-PAGE protein profiles of depleted follicular fluids with MARS-6 showed that albumin was removed completely from HFF and CFF, but again partially from PFF (Fig. 1, column C). In contrast, we observed that both heavy and light chains of immunoglobulins

Table 2. Total protein concentration and the percentage of depletion efficiency in crude and depleted FF samples

\begin{tabular}{|c|c|c|c|}
\hline & \multirow[b]{2}{*}{ Total protein concentration $(\mathrm{mg} / \mathrm{ml}$; mean $\pm \mathrm{SEM})$} & \multicolumn{2}{|r|}{ Depletion efficiency $(\%$; mean \pm SEM) } \\
\hline & & ProteomeLab $^{\mathrm{TM}}$ IgY-HSA & Multiple affinity removal spin cartridge - human 6 (MARS-6) \\
\hline HFF & $81.85 \pm 16.45$ & $87.27 \pm 2.56$ & $81.81 \pm 3.66$ \\
\hline CFF & $85.00 \pm 9.00$ & $83.13 \pm 1.74$ & $78.30 \pm 6.50$ \\
\hline PFF & $91.40 \pm 2.10$ & $84.98 \pm 1.02$ & $72.90 \pm 11.10$ \\
\hline
\end{tabular}

CFF, canine follicular fluid; HFF, human follicular fluid; PFF, porcine follicular fluid; IgY, immunoglobulin yolk.

All values are based on three independent experiments.

Differences are not significant.

The depletion efficiency was calculated with following formula: (Protein amount $(\mu \mathrm{g})$ in crude FF - protein amount $(\mu \mathrm{g})$ in depleted FF $\times 100 \%) /$

(protein amount $(\mu \mathrm{g})$ in crude $\mathrm{FF}$ ). 
(A)
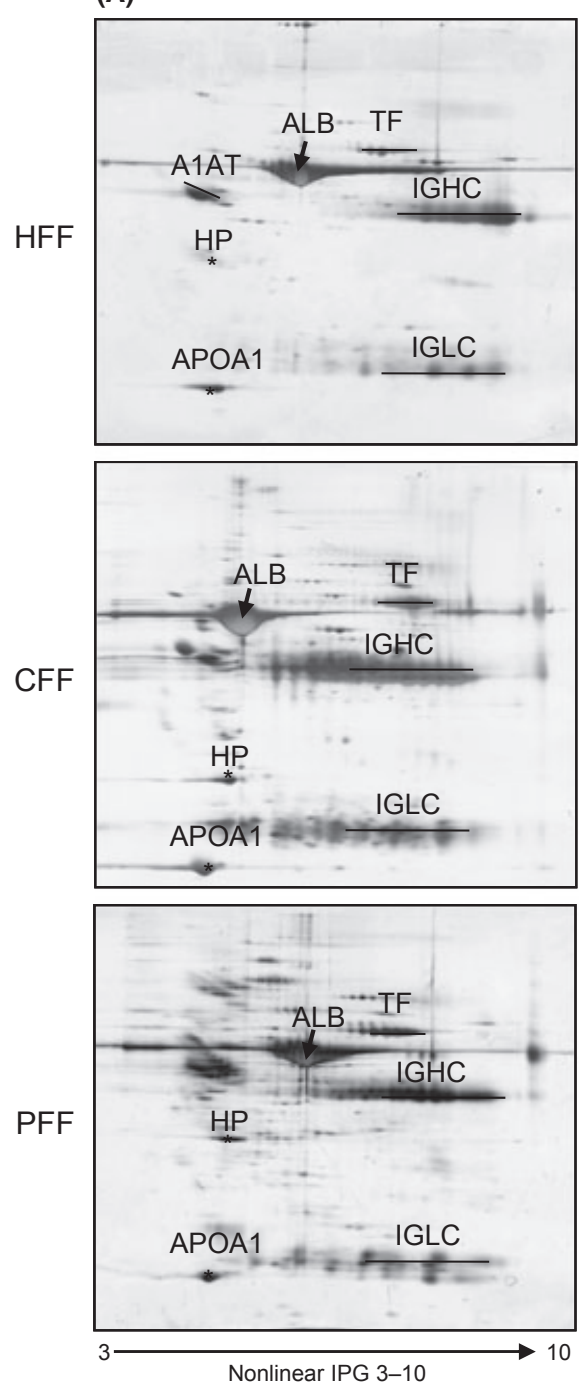

(B) ProteomeLab ${ }^{\mathrm{TM}} \lg \mathrm{Y}-\mathrm{HSA}$
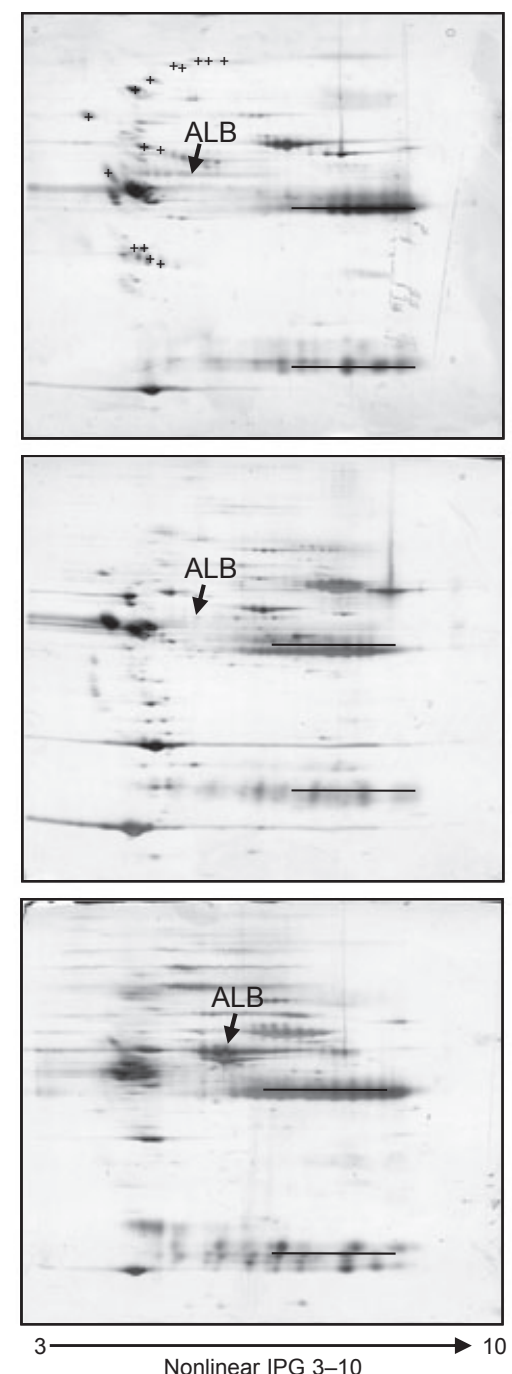

(C)
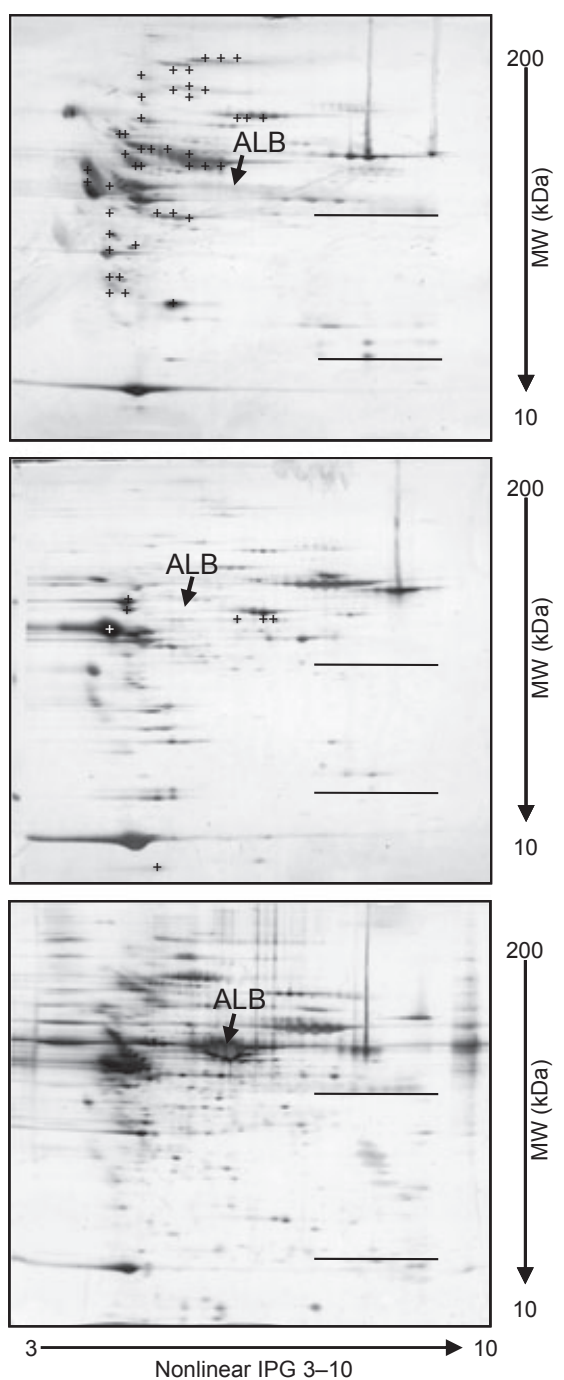

Fig. 1. Representative 2D-PAGE of crude and depleted follicular fluids from human (HFF), porcine (PFF), and canine (CFF). Proteins samples $(100 \mu \mathrm{g})$ were applied to non-linear pH 3-10 IPG strips in the first dimension and then separated on a $10 \%$ SDS-PAGE gel in the second dimension. Proteins were visualized by staining with silver nitrate. The positions of some of high-abundance plasma protein are marked in crude follicular fluid 2D-PAGE: ALB, albumin; A1AT, alpha-1-antitrypsin; TF, transferrin; HP, haptoglobin; APOA1, apolipoprotein A-I; IGHC, immunoglobulin gamma heavy chain; IGLC, immunoglobulin gamma light chain. The '+' on the images shows the appearance of new proteins or increase the intensity of some proteins after immunodepletion (S. Fahiminiya and N. Gérard, personal communications)

were completely depleted in all three species. This result was in accordance with the depletion efficiencies (HFF and $\mathrm{CFF}>\mathrm{PFF}$ ). Figure $1 \mathrm{C}$ clearly showed that $\mathrm{HFF}$ depleted with MARS-6 exhibit many more protein $(+254)$ spots in entire $\mathrm{pH}$ interval as compared with crude samples. Again, this can be explained by the specificity of this immunodepletion column against human proteins. Concerning CFF, some proteins showed a higher intensity after depletion by MARS-6, compared with crude follicular fluid, but no new proteins were revealed. Finally, the effective removal of immunoglobulins from PFF did not exhibit any new proteins after depletion by MARS-6.

Taken together, our data suggest that immunodepletion of the six most highly abundant plasma proteins using the MARS-6 column is more effective at reducing the dynamic range of follicular fluid proteins than the
ProteomeLab $^{\mathrm{TM}} \operatorname{IgY}$-HSA column, and results in the visualization of more medium- and low-abundance follicular fluid proteins by 2D-PAGE.

\section{Conclusion}

This study provides the first comprehensive investigation of commercially available immunodepletion columns, to improve the protein profiling of follicular fluid derived from human, porcine and canine. In this study, we showed that both immunodepletion columns were more effective to remove high-abundance proteins especially albumin from $\mathrm{HFF}$ and CFF, compared with PFF. In addition, new proteins were revealed in HFF 2D-PAGE after depletion by MARS-6. Based on our results, we conclude that both columns are efficient and reproducible methods that can be used in combination 
with 2D-PAGE and/or mass spectrometry before proteomic analysis of human and CFF.

\section{Acknowledgements}

The authors thank Dr Dominique Royère, Dr Joëlle Dupont and Dr Karine Reynaud for providing human and canine follicular fluids, respectively. Pascal Papillier is acknowledged for collecting porcine ovaries from slaughterhouse. SF and NG thank Dr Sylvain Lehmann for accepting them in his laboratory during the test of immunodepletion columns. This research programme was financially supported by INRA, France. Somayyeh Fahiminiya was $\mathrm{PhD}$ student supported by a fellowship from INRA.

\section{Conflict of interests}

None of the authors have any conflict of interest to declare.

\section{Author contributions}

SF carried out immunodepletion, 2D-PAGE analysis of HFF, PFF and CFF, computerized image analysis and drafted the manuscript. SR helped for immunodepletion of follicular fluid samples. NG designed and supervised the study, participated to the immunodepletion of follicular fluid samples and revised the manuscript. All authors read and approved the final manuscript.

\section{References}

Angelucci S, Ciavardelli D, Di Giuseppe F, Eleuterio E, Sulpizio M, Tiboni GM, Giampietro F, Palumbo P, Di Ilio C, 2006: Proteome analysis of human follicular fluid. Biochim Biophys Acta 1764, 1775-1785.

Cabrera VO, Andino NV, Mateo De Acosta O, 1985: Protein electrophoretic patterns of bovine and porcine ovarian follicular fluid. J Endocrinol Invest 8, 489-493.

Fahiminiya S, Reynaud K, Labas V, Batard S, Chastant-Maillard S, Gerard N, 2010: Steroid hormones content and proteomic analysis of canine follicular fluid during the preovulatory period. Reprod Biol Endocrinol 8, 132.

Fortune JE, Rivera GM, Yang MY, 2004: Follicular development: the role of the follicular microenvironment in selection of the dominant follicle. Anim Reprod Sci 82-83, 109-126.
Guerif F, Cadoret V, Poindron J, Lansac J, Royere D, 2003: Overnight incubation improves selection of frozen-thawed blastocysts for transfer: preliminary study using supernumerary embryos. Theriogenology 60, 1457-1466.

Huang L, Harvie G, Feitelson JS, Gramatikoff K, Herold DA, Allen DL, Amunngama R, Hagler RA, Pisano MR, Zhang WW, Fang X, 2005: Immunoaffinity separation of plasma proteins by $\operatorname{IgY}$ microbeads: meeting the needs of proteomic sample preparation and analysis. Proteomics 5, 3314-3328.

Jacobs JM, Adkins JN, Qian WJ, Liu T, Shen Y, Camp DG II, Smith RD, 2005: Utilizing human blood plasma for proteomic biomarker discovery. J Proteome Res 4, 1073-1085.

Linke T, Doraiswamy S, Harrison EH, 2007: Rat plasma proteomics: effects of abundant protein depletion on proteomic anal- ysis, J Chromatogr B Analyt Technol Biomed Life Sci 849, 273-281.

Martosella J, Zolotarjova N, Liu H, Nicol G, Boyes BE, 2005: Reversed-phase high-performance liquid chromatographic prefractionation of immunodepleted human serum proteins to enhance mass spectrometry identification of lower-abundant proteins. J Proteome Res 4, 1522-1537.

Zhang WW, 2003: The use of gene-specific IgY antibodies for drug target discovery. Drug Discov Today 8, 364-371.

Submitted: 3 Jun 2011; Accepted: 13 Oct 2011

Author's address (for correspondence) N Gérard, UMR 6175, INRA, 37380 Nouzilly, France. E-mail: nadine.gerard@tours. inra.fr 